Abstracted/indexed in Academic Search Complete, Agroforestry Abstracts, Asia Journals Online, Bangladesh Journals Online, Biological Abstracts, BIOSIS Previews, CAB Abstracts, Current Abstracts, Directory of Open Access Journals, EMBASE/Excerpta Medica, Google Scholar, HINARI (WHO), International Pharmaceutical Abstracts, Open J-gate, Science Citation Index Expanded, SCOPUS and Social Sciences Citation Index; ISSN: 1991-0088

\title{
Pharmacokinetic/pharmacodynamic based dosing of ciprofloxacin in complicated urinary tract infections
}

\author{
Ana Sabo', Ana Tomas ${ }^{1}$, Nataša Tomiće ${ }^{2}$, Momir Mikov ${ }^{1}$, Olga Horvat ${ }^{1}$, Radmila Popoviće \\ and Zdenko Tomićc
}

${ }^{1}$ Department of Pharmacology, Toxicology and Clinical Pharmacology, Faculty of Medicine, University of Novi Sad, Serbia; ${ }^{2}$ Institute of Emergency medicine, Clinical Centre of Vojvodina, Novi Sad, Serbia.

\begin{tabular}{|c|c|}
\hline \multicolumn{2}{|l|}{ Article Info } \\
\hline $\begin{array}{l}\text { Received: } \\
\text { Accepted: } \\
\text { Available Online: }\end{array}$ & $\begin{array}{l}10 \text { June } 2015 \\
17 \text { June } 2015 \\
12 \text { July } 2015\end{array}$ \\
\hline \multicolumn{2}{|c|}{ DOI: 10.3329/bjp.v10i3.23604 } \\
\hline \multicolumn{2}{|c|}{$\begin{array}{l}\text { Cite this article: } \\
\text { Tomas A, Tomić N, Popović R, Mikov } \\
\text { M, Horvat O, Sabo A, Tomić Z. Phar- } \\
\text { macokinetic / pharmacodynamic } \\
\text { based dosing of ciprofloxacin in com- } \\
\text { plicated urinary tract infections. } \\
\text { Bangladesh J Pharmacol. 2015; 10: } 621 \\
\text {-26. }\end{array}$} \\
\hline
\end{tabular}

\begin{abstract}
Ciprofloxacin is often used in treatment of complicated urinary tract infections in areas with high rates of resistance to first line agents. The aim of this study was to evaluate efficacy of ciprofloxacin in standard dosing regimens in treatment of complicated urinary tract infections. Plasma concentration curves were simulated and minimum inhibitory concentration (MIC) and postantibiotic effect were determined. Ciprofloxacin MIC ranged from 0.0156 for Gram-negative and to $0.125-0.5 \mu \mathrm{g} / \mathrm{mL}$ for Gram-positive bacteria. Both dosing regimens were suitable for eradication of Gram-negative bacteria, with slight supremacy of $750 \mathrm{mg} / 12$ hours over $500 \mathrm{mg} / 12$ hours dosing regimen. Even though all strains were fully susceptible to ciprofloxacin, pharmacokinetic/pharmacodynamic parameters did not meet target thresholds for pathogens with MIC over $0.1-0.2 \mu \mathrm{g} / \mathrm{mL}$ regardless of the administered dose. Ciprofloxacin remains an excellent choice for treatment of complicated urinary tract infections caused by Gram-negative bacteria, but in infection caused by Gram-positive strains, deeper analysis is necessary in order to achieve optimal results.
\end{abstract}

\section{Introduction}

Urinary tract infections are among the most common community bacterial infections. urinary tract infections with involvement of upper urinary tract portions, occurring in patients with underlying diseases (diabetes mellitus, immunosuppression) (Krcmery and Naber, 1999) or structural abnormalities of urinary tract are classified as complicated urinary tract infections (Nicolle, 2005). Ciprofloxacin and other fluoroquinolones have become a popular treatment option for patients with complicated urinary tract infections in areas with higher rates of resistance to traditionally used antibacterial agents such as trimethoprimsulfamethoxazole and aminopenicillins (Van Bambeke et al., 2005; Finch, 2000). However, excessive use of ciprofloxacin that has led to a considerable and worrying increase in the rate of resistant isolates
(Daoud et al., 2014) which raises a question of adequacy of current dosing strategies. The outcome of antibiotic treatment depends on several complex interactions between the infectious agent, antimicrobial drug and host defense mechanisms, and treatment outcome shows high variability of the dose-response relationship (Jacobs, 2001; Wilspelwey, 2005). For the optimal clinical outcome, high concentrations at the site of the infection are critical for fluoroquinolones (Drussano et al., 2004). This is reflected in the peak concentration and area under the concentration-time curve being the main pharmacokinetic parameters taken into account when discussing efficacy indices for ciprofloxacin (Mueller et al., 2004). In past decades, the importance of pharmacodynamic parameters- mainly mechanism of bacterial eradication and postantibiotic effect has also been recognized and an answer to complexity of antibioticmicroorganism interaction has been found in a quanti- 
tative relationship between pharmacokinetic parameters of antibacterial drugs and a microbiological parameter constituted in a pharmacokinetic/pharmacodynamics indices which correlate with therapeutic outcome. For fluoroquinolones, parameters that correlate best with the clinical efficacy are the $\mathrm{AUC}_{24} / \mathrm{MIC}$ [ratio between 24-hours area under the concentrationtime curve and the minimum inhibitory concentration (MIC)] and $\mathrm{C}_{\max } / \mathrm{MIC}$ ratio (Jacobs, 2001; Wispelwey, 2005). One of the strong suits of fluoroquinolones, the postantibiotic effect also has the impact on dosing strategies. Presence of postantibiotic effect, the suppression of bacterial growth following limited exposure of organisms to antimicrobial (Craig, 2001), may improve the therapeutic outcome in case of margin pharmacokinetic/pharmacodynamics index values and may provide administration at longer dosing intervals.

The aim of this study was to determine the effect of ciprofloxacin on urinary bacterial isolates, determine the postantibiotic effect and incorporate this information with pharmacokinetic profile of ciprofloxacin in order to evaluate current standard dosing regimen of $500 \mathrm{mg} / 12$ hours and $750 \mathrm{mg} / 12$ hours for orally administered ciprofloxacin in complicated urinary tract infections.

\section{Materials and Methods}

\section{Pharmacokinetic simulation}

In order to obtain pharmacokinetic parameters (AUC, $\mathrm{C}_{\max }$ ) necessary for calculation of efficacy indices, simulation was performed using literary values of the pharmacokinetic parameters for one-compartment model $\left(\mathrm{F}, \mathrm{V}_{\mathrm{d}}, \mathrm{K}_{\mathrm{a}}, \mathrm{K}_{\mathrm{e}}\right)$ using a methodology described previously (Navarro et al., 2002a; Navarro et al., 2002b). Time-concentration curves were simulated for $500 \mathrm{mg}$ and $750 \mathrm{mg}$ twice daily orally administered ciprofloxacin. Simulation was carried out using WinNonlin ${ }^{\circledR}$ Version 4.1 by Pharsight Corporation. First-order input, first-order output, and no lag time model from WinNonlin Model Library was used. Input for volume of distribution $\left(\mathrm{V}_{\mathrm{d}}\right)$ was expressed in liters using standard weight of $70 \mathrm{~kg}$. Dosing parameters including the number of doses (3), amount of the dose (500 mg and $750 \mathrm{mg}$ ), and dosing time (0 hour and 12 hours) were entered and simulation was performed. Bioavailability $(\mathrm{F})$ was included into dose calculation. For model used, $\mathrm{K}_{\mathrm{a}}$, the absorption rate constant, is the rate at which drug enters the central compartment from outside the system, and $K_{e}$, the elimination rate constant, is the rate at which drug leaves the system from the central compartment. Pharmacokinetic parameters used for simulations were: $\mathrm{F}=0.7, \mathrm{k}_{\mathrm{a}}=2.5 \mathrm{~h}^{-1}$, $\mathrm{V}_{\mathrm{d}}=3.7 \mathrm{~L} / \mathrm{kg}$ and $\mathrm{k}_{\mathrm{e}}=0.19 \mathrm{~h}^{-1}$ (Navarro et al., 2002b).

\section{Bacterial strains and media}

Two Gram negative (Escherichia coli, Proteus mirabilis) and two Gram positive strains (Staphylococcus aureus, S. epidermidis) from clinical urinary isolates were supplied by Institute of public health of Vojvodina, Center of Microbiology. The strains were cultured in MuellerHinton broth (Torlak Institute, Belgrade, Serbia) and Mueller-Hinton agar (Torlak Institute, Belgrade, Serbia) was used for determination of viable counts. Inoculums were replenished day before the experiments to ensure the logarithmic phase of growth at the time of the exposure to antibiotic. Inoculum was prepared making a direct saline suspension colonies from a pure culture, and it was adjusted using a densitometer to achieve a 0.5 McFarland turbidity standard (this leads to a suspension containing approximately $1 \times 10^{8} \mathrm{CFU} / \mathrm{mL}$ ).

\section{Antimicrobial agents and MIC determination}

The antimicrobial agent used was ciprofloxacin (Zdravlje Leskovac, Serbia) and stock solution from dry powder was prepared according to manufacturer's recommendations. The MIC was determined for each isolate using the broth dilution method defined by Clinical and Laboratory Standards Institute standards (CLSI, 2006). Serial two-fold dilutions of ciprofloxacin ranging from 8 to $0.0039 \mu \mathrm{g} / \mathrm{mL}$ were prepared in Mueller-Hinton broth. During testing, multiple standard test tubes were filled with broth containing varying concentrations of the ciprofloxacin and the culture suspension was then added to the tubes. The tubes were incubated at $37^{\circ} \mathrm{C}$ for 24 hours. Following the incubation, the tubes were checked for bacterial growth. If the broth became cloudy or a layer of cells has made at the bottom, then bacterial growth has ensued. The results of the broth dilution method are reported in MIC, or the lowest concentration of antibiotics that stopped bacterial growth. For every strain, testing was performed in triplicates, and results were displayed as a mean value.

\section{Postantibiotic effect determination}

Postantibiotic effect of ciprofloxacin was determined using methodology described previously (Spangler et al., 1998). Tubes were filled to a final volume of $5 \mathrm{~mL}$ with $0.5 \mathrm{~mL}$ bacterial suspension, $4.4 \mathrm{~mL}$ of MuellerHinton broth and $0.1 \mathrm{~mL}$ of previously prepared saline and antibiotic mixture (only $0.1 \mathrm{~mL}$ saline solution was added to the negative controls). Bacteria were subjected to the ciprofloxacin concentration of $1 / 2 \times \mathrm{MIC}, 1 \times \mathrm{MIC}$ and $4 \times \mathrm{MIC}$. The final inoculum was $10^{6}$ to $10^{7} \mathrm{CFU} /$ $\mathrm{mL}$. Control tubes and antibiotic-containing tubes were incubated in a $37^{\circ} \mathrm{C}$ water bath. The time of antibiotic exposure was 1 hour and 2 hours. After the incubation time, antibiotics were removed using dilution method (1: 1000-10000) with antibiotic free broth. Thereafter, 10$\mu \mathrm{L}$ samples were plated onto the surfaces of MuellerHinton agar plates. This was defined as zero time after antibiotic removal. Diluted suspensions of bacteria were further incubated at $37^{\circ} \mathrm{C}$ for 6 hours, and at 


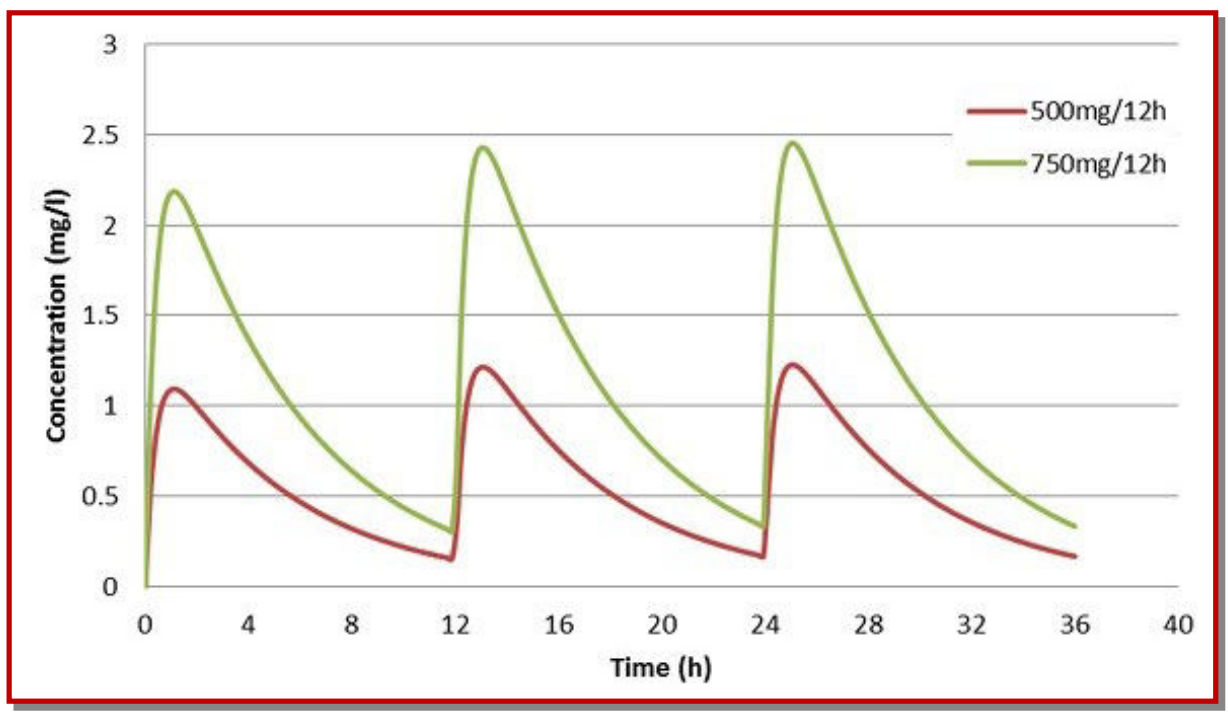

Figure 1: Simulated ciprofloxacin concentrations in plasma for the dosage regimens of $500 \mathrm{mg} / 12$ hourly and $750 \mathrm{mg} / 12 \mathrm{hourly}$

hourly intervals $0.5 \mathrm{~mL}$ was removed and plated onto agar. A control, antibiotic free culture was handled in the same manner. Viability count was used to determine and compare the growth kinetics of bacterial colonies exposed to the antibiotic and negative control group and time-growth curves were constructed. The number of viable bacteria was determined at zero time after the antibiotic removal and at hourly intervals for next 6 hours. The PAE was calculated with the standard formula of Craig and Gudmundsson (Craig and Gudmundsson, 1996), as a difference in time necessary for the colony forming units to increase 10-fold (desired increase of $1 \log ^{10}$ ) between test and control cultures from the count observed at zero time. A 10-fold growth rate increase was arbitrarily chosen because beyond that level, the rate of growth of the organisms exposed to the antibiotic is the same as that of the untreated controls.

\section{Pharmacokinetic/pharmacodynamics parameters}

By using in vitro MIC data and simulated plasma profiles, the pharmacokinetic/pharmacodynamic markers of antimicrobial activity (AUC/MIC and $\mathrm{C}_{\max }$ / $\mathrm{MIC}$ ) were determined. AUC/MIC and $\mathrm{C}_{\max } / \mathrm{MIC}$ were calculated as the area under the concentration-time curve or the highest concentration reached over 24 hours divided by determined MIC values of tested pathogens. These results were incorporated with postantibiotic effect duration, in order to fully grasp pharmacodynamic profile of ciprofloxacin. Pharmacokinetic/pharmacodynamic breakpoints targeting desired thresholds of AUC/MIC of 125 (Forest et al., 1993) and $\mathrm{C}_{\max } / \mathrm{MIC}$ of 10 (Drusano et al., 2004) have also been determined. These breakpoints represent the highest MIC in which the target pharmacokinetic/ pharmacodynamic indices values would be reached with tested dosing regimens.

\section{Results}

Figure 1 shows simulated plasma curves corresponding to dosage regimens of $500 \mathrm{mg} / 12$ hours and $750 \mathrm{mg} / 12$ hours of ciprofloxacin for patients with standard weight of $70 \mathrm{~kg}$. The MIC determined for ciprofloxacin on different bacterial strains ranged from $0.0156 \mu \mathrm{g} / \mathrm{mL}$ for Escherichia coli and Proteus mirabilis, $0.125 \mu \mathrm{g} / \mathrm{mL}$ for $S$. aureus to $0.5 \mu \mathrm{g} / \mathrm{mL}$ for $S$. epidermidis. Table I shows

\begin{tabular}{|c|c|c|c|c|c|}
\hline \multicolumn{6}{|c|}{ Table I } \\
\hline \multicolumn{6}{|c|}{ Postantibiotic effect induced by ciprofloxacin on different bacterial strains } \\
\hline \multirow{2}{*}{$\begin{array}{l}\text { Incubation } \\
\text { time }\end{array}$} & \multirow{2}{*}{$\begin{array}{c}\text { Antibiotic } \\
\text { concentration }\end{array}$} & \multicolumn{4}{|c|}{ Duration of postantibiotic effect (hour) } \\
\hline & & Escherichia coli & Proteus mirabilis & Staphylococcus epidermidis & Staphylococcus aureus \\
\hline \multirow{3}{*}{1 hours } & $1 / 2$ MIC & 0.75 & 0.50 & 0.48 & 0.50 \\
\hline & $1 \mathrm{MIC}$ & 0.83 & 0.78 & 0.65 & 0.53 \\
\hline & $4 \mathrm{MIC}$ & 0.93 & 1.23 & 1.42 & 1.35 \\
\hline \multirow{3}{*}{2 hours } & $1 / 2 \mathrm{MIC}$ & 0.90 & 0.83 & 1.68 & 0.65 \\
\hline & $1 \mathrm{MIC}$ & 1.08 & 1.07 & 1.83 & 0.93 \\
\hline & $4 \mathrm{MIC}$ & 2.20 & 2.13 & 2.60 & 2.18 \\
\hline
\end{tabular}


Table II

Pharmacokinetic/pharmacodynamics efficacy indices and pharmacokinetic/pharmacodynamics breakpoints following orally administered ciprofloxacin

\begin{tabular}{|c|c|c|c|c|}
\hline \multirow[t]{2}{*}{ PK/PD index } & $\begin{array}{l}\text { Escherichia coli, Proteus } \\
\text { mirabilis (MIC } 0.0156 \text { ) }\end{array}$ & $\begin{array}{l}\text { Staphylococcus } \\
\text { epidermidis (MIC 0.5) }\end{array}$ & $\begin{array}{l}\text { Staphylococcus aureus } \\
\text { (MIC 0.125) }\end{array}$ & PK/PD breakpoint \\
\hline & AUC/MIC & AUC/MIC & AUC/MIC & Target AUC/MIC >125 \\
\hline 500 mg 12 hourly & 859.0 & 26.8 & 107.2 & $0.1 \mu \mathrm{g} / \mathrm{mL}$ \\
\hline \multirow[t]{2}{*}{750 mg 12 hourly } & 1718.2 & 53.6 & 214.4 & $0.2 \mu \mathrm{g} / \mathrm{mL}$ \\
\hline & $\mathrm{C}_{\max } / \mathrm{MIC}$ & $\mathrm{C}_{\max } / \mathrm{MIC}$ & $\mathrm{C}_{\max } / \mathrm{MIC}$ & Target $\mathrm{C}_{\max } / \mathrm{MIC}>10$ \\
\hline 500 mg 12 hourly & 78.2 & 2.4 & 9.8 & $0.1 \mu \mathrm{g} / \mathrm{mL}$ \\
\hline 750 mg 12 hourly & 154.5 & 4.8 & 19.3 & $0.2 \mu \mathrm{g} / \mathrm{mL}$ \\
\hline
\end{tabular}

duration of postantibiotic effect induced by ciprofloxacin on different bacterial strains. Positive postantibiotic effect was found for all isolates subjected to the effect of ciprofloxacin. Postantibiotic effect duration varied between different bacterial strains, as well as between different concentrations and exposure times. For these isolates, ciprofloxacin induced postantibiotic effect ranging from 0.48 - 2.60 hours for Gram positive strains, and from 0.50 - 2.30 hours for Gram negative strains. Integrated pharmacokinetic/pharmacodynamic parameters for the simulated pharmacokinetic data and the MIC measured in vitro are displayed in Table II.

Dosing regimens of $500 \mathrm{mg} / 12$ hours and $750 \mathrm{mg} / 12$ hours produced variable $\mathrm{AUC} / \mathrm{MIC}$ and $\mathrm{C}_{\max } / \mathrm{MIC}$ values. Both regimens were equally efficient, with values high above desired range on microorganisms with lowest MIC (E. colli and P. mirabillis), while neither were sufficient for S. epidermidis, with MIC of $0.5 \mu \mathrm{g} /$ $\mathrm{mL}$. For S. aureus, $500 \mathrm{mg} / 12$ hours dosing regimen comes close to target values, while $750 \mathrm{mg} / 12$ hours produces values sufficiently high for eradication of this microorganism. Pharmacokinetic/pharmacodynamic breakpoints, which illustrate the MIC values for which main pharmacokinetic/pharmacodynamic ratios reach values required for clinical success (Jacobs, 2001) were in range of $0.1-0.2 \mu \mathrm{g} / \mathrm{mL}$.

\section{Discussion}

Fluoroquinolones are often used as the drugs of choice for the empirical treatment of uncomplicated and complicated urinary tract infections. A 10-day course of ciprofloxacin is recommended for patients with complicated urinary tract infections or acute pyelonephritis, if the causative uropathogen is susceptible (Chen et al., 2013). Though usually successfully treated with antibiotics, complicated urinary tract infections are often incompletely resolved by antibiotic therapy and frequently recur either through relapse or recurrent infection (Barber et al., 2013). As stated before, for the optimal clinical outcome, high concentrations at the site of the infection are critical for fluoroquinolones (Drusano et al., 2004). For fluoroquinolones, at $C_{\max } /$ MIC ratio >10 (Drusano et al., 2004), this is the best predictor of clinical outcome, but at lower peak concentrations, AUC/MIC ratio is of better predictive value. AUC/MIC value > 25 might be sufficient for less severe infections and/or immunocompetent hosts, but with a value of $>100$ appear necessary for severe infections and/or immune-compromised hosts (Jacobs, 2001). However, level of AUC/MIC of 125 established in the study of pharmacodynamics of ciprofloxacin in critically ill has been widely accepted as an endpoint that correlates best with rapid bacteriologic and clinical responses (Forest et al., 2004).

In evaluation of adequacy of ciprofloxacin in treatment of complicated urinary tract infections ciprofloxacin was tested on 4 different bacterial strains from urinary isolates. Ciprofloxacin showed excellent effect on Escherichia and Proteus strains but even though all strains were listed as susceptible according to the microbiological standards, pharmacokinetic/pharmacodynamic evaluation suggested that plasma concentrations reached using standard dosing regimens (500 $\mathrm{mg} / 12$ hours and $750 \mathrm{mg} / 12$ hours) were not adequate to successfully treat infections caused by all tested pathogens. Influence of the type of the pathogen causing the infection on pharmacokinetic/pharmacodynamic breakpoints is reflected in the MIC value. Microorganisms listed as susceptible can have wide range of actual MIC values, and since MIC are reported in multiplication factors of two, with each level of decreased susceptibility a two-fold increase in pharmacokinetic component of pharmacokinetic/pharmacodynamic is necessary to maintain the target ratio (Schentag, 2000). Clinical breakpoints are used in clinical microbiology laboratories to categorize microorganisms as clinically susceptible, intermediate or resistant depending on the quantitative antimicrobial susceptibility as indicated by the MIC value determined in a well-defined standard test system (Mouton et al.,2012). However, whether the results of the in vitro 
susceptibility testing of bacterial isolates to fluoroquinolones can predict the clinical outcome of patients with urinary tract infections, especially complicated urinary tract infections, is controversial (Chen et al., 2013). Clinicians rely on laboratory reports of susceptibility of microorganism to an antibiotic when determining the potential use of an antibiotic in treatment of infection. Susceptibility breakpoint of $1 \mu \mathrm{g} / \mathrm{mL}$ for ciprofloxacin may categorize significant numbers of isolates as susceptible when evidence suggests that not all complicated urinary tract infections caused by these isolates can be successfully treated with ciprofloxacin. For an example, with the MIC $0.5 \mu \mathrm{g} / \mathrm{mL}$ this strain of S. epidermidis is susceptible to ciprofloxacin but AUC/ MIC ratios are much lower than the desired threshold of 125 even for maximum dose of $750 \mathrm{mg}$. These findings indicate the necessity of reevaluating current breakpoints used for ciprofloxacin in our standard testing. Pharmacokinetic/pharmacodynamic breakpoints, which illustrate the MIC values for which main pharmacokinetic/pharmacodynamic ratios reach values required for clinical success (Jacobs, 2001) indicate for MIC over $0.2 \mu \mathrm{g} / \mathrm{mL}$ ciprofloxacin, may not provide eradication of susceptible organisms. Also, an interesting insight into complexity of ciprofloxacin pharmacodynamics has been provided by the presence of time dependent postantibiotic effect noted in this study. Duration of postantibiotic effect observed in our study is in accordance with previous research where duration of postantibiotic effect induced by ciprofloxacin on Gram negative bacteria was 1-2.2 hours (Minguez et al., 1991) and 1.1-2.4 hours on Gram positive (Licata et al., 1997). While, as expected, ciprofloxacin exhibited strong concentration-dependent postantibiotic effect, time-dependent postantibiotic effect was also detected. At the same antibiotic concentrations postantibiotic effect duration increased with prolonged exposure to antibiotic. For instance, at concentration of 4 times the MIC for Proteus mirabilis after incubation for 1 and 2 hours, postantibiotic effect has increased from 1.23 to 2.13 hours prospectively. Same was observed for all 4 bacterial strains, bur timedependent postantibiotic effect was the most prominent at higher concentrations. This shows that that not only concentration of ciprofloxacin plays an important role in bacterial killing but that time of exposure to antibiotic is also significant. This was also demonstrated in a study by Zelenitsky et al. showed that the AUC/ MIC was most strongly associated with bactericidal activity and the $\mathrm{C}_{\max }$ / MIC was most predictive of early bacterial killing the time at which levels of drug exceed the MIC ( $t>M I C)$ was significantly associated with the final bacterial counts at 24 hours (Zelenitsky et al., 2003). For example, a $\mathrm{T}>\mathrm{MIC}$ value of $<55 \%$ of the dosing interval was only bacteriostatic and maximal antibacterial response at 24 hours was associated with $\mathrm{t}>\mathrm{MICs}>70 \%$. Importance of adequate dosing intervals lies in the fact that the same AUC/MIC ratio can be obtained with different dosing regimens but can result in different $\mathrm{C}_{\max } / \mathrm{MIC}$ or $\mathrm{T}>\mathrm{MIC}$ parameters (Scaglione et al., 2003). Other important application of pharmacokinetic/pharmacodynamic breakpoints in choosing the dosing regimen lies in the fact that maximizing the T>MIC and AUC/MIC may offer an opportunity to limit the development of resistance to fluoroquinolones. Low concentrations at the end of the dosing interval may promote bacterial resistance. The concept of mutant prevention concentration refers to the concentration that prevents the growth of not only fully susceptible, but also low resistant strains (Blondeau et al., 2004; Olofsson et al., 2006). Keeping the concentration of drug above the mutant prevention concentration during entire dosing interval and providing AUC/MIC ratios as high as possible reduces the potential of resistance selection (Firsov et al., 2003).

\section{Conclusion}

Ciprofloxacin in standard dosing regimen remains a good choice of antibiotic for treatment of complicated urinary tract caused by susceptible Gram negative microorganisms, but in severe, recurrent or chronic infections, especially those caused by Gram positive bacteria which often have higher MIC values, deeper analysis is necessary in order to achieve optimal results.

\section{Acknowledgement}

This work was supported by the Ministry of Science and Technological Development of Serbia project No. III 41012.

\section{References}

Ambrose PG. Antimicrobial susceptibility breakpoints: PK-PD and susceptibility breakpoints. Treat Respir Med. 2005; 4 (Suppl 1): 5-11.

Barber A, Norton J, Spivak A, Mulvey M. Urinary tract infections: Current and emerging management strategies. Clin Infect Dis. 2013; 57: 719-24.

Blondeau J, Hansen G, Metzler K, Hedlin P. The role of PK/PD parameters to avoid selection and increase of resistance: Mutant prevention concentration. J Chemother. 2004; 16 (Suppl 3): 1-19.

Chen YH, Ko WC, Hsueh PR. Emerging resistance problems and future perspectives in pharmacotherapy for complicated urinary tract infections. Expert Opin Pharmacother. 2013; 14: 587-96.

Clinical and Laboratory Standards Institute. Methods for dilution antimicrobial susceptibility tests for bacteria that grow aerobically: Approved standard. 7th ed. Clinical and Laboratory Standards Institute document M7-A7. Clinical and Laboratory Standards Institute, 2006. 
Craig WA. Does the Dose Matter? Clin Infect Dis. 2001; 33 (Suppl 3): 233-37.

Craig WA, Gudmundsson S: Postantibiotic effect. In: Antibiotics in laboratory medicine. 4th ed. Baltimore MD, Williams \& Wilkins, 1996, pp 296-329.

Daoud Z, Sokhn ES, Azar E, Masri K, Doron S. Mutant prevention concentrations of ciprofloxacin against urinary isolates of Escherichia coli and Klebsiella pneumonia. J Infect Dev Ctries. 2014; 8: 154-59.

Drusano G L, Preston S, Fowler C, Corrado M, Weisinger B, Kahn J: Relationship between fluoroquinolone area under the curve: Minimum inhibitory concentration ratio and the probability of eradication of the infecting pathogen, in patients with nosocomial pneumonia. J Infect Dis. 2004; 189: 1590-97.

Finch R. Ciprofloxacin: Efficacy and indications. J Chemother . 2000; 12 Suppl: 15-17.

Firsov A, Vostrov S, Lubenko I, Drlica K, Portnoy Y, Zinner S: In vitro pharmacodynamic evaluation of the mutant selection window hypothesis using four fluoroquinolones against Staphylococcus aureus. Antimicrob Agents Chemother. 2003; 47: 1604-13.

Forrest A, Nix DE, Ballow $\mathrm{CH}$, Goss TF, Birmingham MC, Schentag JJ. Pharmacodynamics of intravenous ciprofloxacin in seriously ill patients. Antimicrob Agents Chemother. 1993; 37: 1073-81.

Jacobs MR. Optimisation of antimicrobial therapy using pharmacokinetic and pharmacodynamic parameters. Clin Microbiol Infect. 2001; 7: 589-96.

Krcmery S, Naber KG. Ciprofloxacin once versus twice daily in the treatment of complicated urinary tract infections. Int J Antimicrob Agents. 1999; 11: 133-38.

Licata L, Smith C, Goldschmidt R, Barrett J, Frosco M. Comparison of the postantibiotic and postantibiotic sub-MIC effects of levofloxacin and ciprofloxacin on Staphylococcus aureus and Streptococcus pneumoniae. Antimicrob Agents Chemother. 1997; 41: 950-55.

Minguez F, Ramos C, Barrientos S, Loscos A, Prieto J. Postantibiotic effect of ciprofloxacin compared with that of five other quinolones. Chemotherapy 1991; 37: 420-25.

Mouton JW, Brown DF, Apfalter P, Cantón R, Giske CG, Ivanova M, MacGowan AP, Rodloff A, Soussy CJ, Steinbakk M, Kahlmeter G. The role of pharmacokinetics/pharmacodynamics in setting clinical MIC breakpoints: The EUCAST approach. Clin Microbiol Infect. 2012; 18: E37-E45.
Mueller M, de la Pena A, Derendorf H. Issues in pharmacokinetics and pharmacodynamics of anti-infective agents: Kill curves versus MIC. Antimicrob Agents Chemother. 2004; 48: 369-377.

Nicolau P. Optimizing outcomes with antimicrobial therapy through pharmacodynamic profiling. J infect Chemother. 2003; 9: 292-96.

Nicolle LE: Complicated urinary tract infections in adults. Can J Infect Dis Med Microbiol. 2005; 16: 349-60.

Olofsson S, Marcusson L, Komp Lindgren P, Hughes D, Cars O. Selection of ciprofloxacin resistance in Escherichia coli in an in vitro kinetic model: Relation between drug exposure and mutant prevention concentration. J Antimicrob Chemother. 2006; 57: 1116-21.

Navarro SM, Coloma Milano C, Zarzuelo Castañeda A, Sayalero Marinero ML, Sánchez-Navarro A. Pharmacokinetics of ciprofloxacin as a tool to optimise dosage schedules in community patients. Clin Pharmacokinet. 2002a; 41: 1213-20.

Navarro SM, Sayalero Marinero M, Sánchez Navarro A. Pharmacokinetic/pharmacodynamic modeling of ciprofloxacin $250 \mathrm{mg} / 12 \mathrm{~h}$ versus $500 \mathrm{mg} / 24 \mathrm{~h}$ for urinary infections. J Antimicrob Chemother. 2002b; 50: 67-72.

Scaglione F, Mouton J, Mattina R, Fraschini F: Pharmacodynamics of levofloxacin and ciprofloxacin in a murine pneumonia model: Peak concentration/MIC versus area under the curve/MIC ratios. Antimicrob Agents Chemother. 2003; 47: 2749-55.

Schentag J. Clinical pharmacology of the fluoroquinolones: Studies in human dynamic/kinetic models. Clin Infect Dis. 2000; 31(Suppl 2): 40-44.

Spangler SK, Lin G, Jacobs MR, Appelbaum PC. Postantibiotic effect and postantibiotic sub-MIC effect of levofloxacin compared to those of ofloxacin, ciprofloxacin, erythromycin, azithromycin, and clarithromycin against 20 Pneumococci. Antimicrob Agents Chemother. 1998; 42: 1253.

Van Bambeke F, Michot J, Van Eldere J, Tulkens P. Quinolones in 2005: An update. Clin Microbiol Infect. 2005; 11: 256-80.

Wispelwey B. Clinical implications of pharmacokinetics and pharmacodynamics of fluoroquinolones. Clin Infect Dis. 2005; 41(Suppl 2): 127-35.

Zelenitsky S, Ariano R, Iacovides H, Sun S, Harding G. AUC ${ }_{(0-}$ t)/MIC is a continuous index of fluoroquinolone exposure and predictive of antibacterial response for Streptococcus pneumoniae in an in vitro infection model. J Antimicrob Chemother. 2003; 51: 905-11.

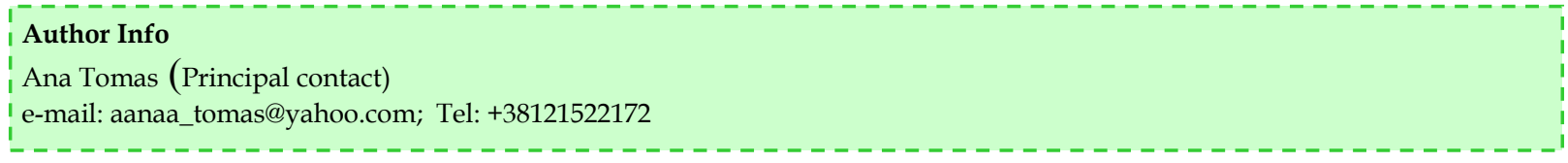

